\title{
THE INFLUENCE OF THE SYMPATHETIC NERVOUS SYSTEM ON THE CAPILLARIES DURING PASSIVE CONGESTION
}

\author{
BY J. HAMILTON CRAWFORD
}

(From the Departments of Physiology and Medicine, Long Island College Hospital)

(Received for publication April 8, 1929)

With the discovery of vasomotor nerves by Claude Bernard the importance of the autonomic nervous system in circulatory regulation came to be recognized. The action of the sympathetic nerves on the arteries and arterioles was definitely established but it has taken many years for any action by them on the capillaries to become accepted. Indeed the capillaries were considered merely passive endothelial tubes whose variation depended on changes which took place in the other parts of the vascular system. In 1860 Beale (1) described nerves accompanying the capillaries and Glaser (2) considered these to be sympathetic nerves. The connection of these nerves to the vessel wall, however, still remains uncertain. Among the early papers Steinach and Kahn (3) presented the most positive evidence that nerve stimulation could influence the capillaries independent of its action on other vessels. They showed that stimulation of the third, fourth and fifth thoracic nerve roots at their exit from the cord produced emptying of the capillaries in the nictating membrane of the frog when the circulation was at a standstill. Krogh, Harrop and Rehberg (4) confirmed this by stimulating the lower ganglia (8-10) of the sympathetic in the frog while studying the vessels in the web under the microscope. They found that the arterioles contracted first and a few seconds later the capillaries contracted independently. The first evidence of capillary contraction following nerve stimulation in mammals was presented by Hooker (5), who stimulated the cervical sympathetic in the cat while he watched the capillaries in the depilated ear under the microscope. He observed a contraction of the capillaries independent of that of the arterioles. The most conclusive evidence of the independent contractility of the 
capillaries following nerve stimulation is that brought forward recently by Harris and Marvin (6). They studied the effect of stimulation of the cervical sympathetic on the vessels in the ear of the albino rabbit. They were able to confirm Hooker's observations but they also showed that stimulation of the sympathetic caused emptying of the capillaries when the circulation was brought to a standstill by obstructing the arterial supply. Under the conditions of their experiment the effect of contraction of the arterioles or venules on the size of the capillaries would obviously have been to distend them, and not to cause them to disappear. As the result of the investigations described there can be little doubt that the sympathetic nervous system can cause contraction of the capillaries independent of its action on the other parts of the vascular system.

The evidence for a supply of vasodilator nerves to the capillaries is much less certain. Doi (7), Krogh, Harrop and Rehberg (4) and Langley (8) (9) have studied this problem and believe that such exist. They all used frogs, except Langley who used the cat's paw, and found that peripheral stimulation of posterior root ganglia or sensory nerves produced vasodilation. They endeavored to rule out the action on the arterioles by various means; Doi by dilating the arterioles with acetylcholine and Langley by occluding the circulation before applying the stimulus. Lewis and Marvin (10) repeated Langley's experiment in cats in which the sympathetic nerves had degenerated and still obtained dilatation.

Knowing the importance of vasomotor reactions to the efficient working of the normal body and having established the powerful influence of the autonomic nervous system on these reactions in all parts of the vascular system, it is important to find out whether variations in them occur in certain pathological conditions in which the flow in the vessels is abnormal. A fruitful field of investigation seemed to be the study of the vascular reactions of the capillaries during passive congestion. The abnormality of the blood flow in the capillaries in cases of advanced heart disease with chronic passive congestion and cyanosis has been described frequently. It has seemed to the author that these patients as compared to normal individuals showed a delayed and even diminished response to various stimuli such as the sudden change from a hot to a cold temperature or vice versa, fright, 
etc. If this is so its importance to the organism must be very great. In order to see whether this was so the effect of stimulation of the cervical sympathetic on the capillaries of the ear during passive congestion has been compared to the normal reaction.

Albino rabbits of 1.5 to 2 kilos were used for the experiments. Ether was used as the anesthetic. At first considerable difficulty was experienced in obtaining a satisfactory production of congestion. Compression of the veins in the neck proved unsatisfactory as the collateral circulation was too free. Compression of the base of the ear would have sufficed but by this means a reduction of the arterial supply would have been obtained also. Finally the problem was solved by dissecting out the main ear veins and producing the requisite amount of traction on them by means of loops of thread passed under the veins. The sympathetic nerve was exposed on the side corresponding to the ear used and was stimulated by faradic current. The ear was fixed flat on the stage of a Leitz microscope and mineral oil was applied to its surface. The magnification used to study the capillaries was 40 times. Light was provided by a 5 ampere direct current arc lamp. It passed through a condenser and then a filter which contained a solution composed of a mixture of copper sulphate and potassium dichromate. This solution was green in color so that besides removing the heat rays it provided a better contrast between the capillaries and the tissues than was given when ordinary light was used. The light was reflected from the mirror of the microscope through the rabbit's ear. By means of this a very satisfactory view of the small vessels in the ear was obtained.

When the preparation had been set up the capillaries were watched under the microscope while an assistant stimulated the sympathetic. The efficacy of the latter was controlled by observation of the pupil. The time during which stimulation was applied was measured by a stop-watch. At first the changes were studied under normal conditions, then congestion was produced for a period varying from fifteen to twenty minutes and the sympathetic again stimulated. Finally observations were repeated from time to time after the venous obstruction had been removed. As far as possible the same capillaries were observed during each period.

Four experiments of this nature were performed and all gave the 
same result. In the normal state the effect was to produce after a short latent period a marked pallor due to contraction of the arterioles. When this occurred the corpuscles in the capillaries became clumped together and the flow stopped. After a short but definite interval the corpuscles again began to move toward the vein and were finally expelled so that the capillary disappeared from view. During this latter period no fresh corpuscles were seen to enter the capillary from the arteriole. There was no doubt that the two changes described were separate processes. The latent period after which these changes took place was practically constant in repeated observations. When venous congestion was produced the ear became definitely cyanotic. The capillaries were dilated and their flow markedly altered. All gradations were seen between complete stasis and those in which there was little change from normal. The rate of flow was much reduced in the majority and was comparable to the condition which had been observed in advanced cases of heart disease (11) (12).

The flow in the different capillaries varied from time to time as had been seen also in heart cases. The capillaries particularly studied were those in which the rate of flow was considerably reduced. In these no contraction was obtained from stimulation even when it was continued for five or six times as long as had been necessary to cause disappearance of the capillaries under normal conditions Some capillaries were observed in which the flow was only moderately reduced and in these contraction took place after a prolonged latent period. In those in which the flow was almost normal the latent period was only slightly increased. On removing the venous obstruction it was found that gradual recovery took place. Capillaries which had failed to contract during the period of obstruction began to contract after a long latent period. The latent period became less and less until finally it reached the normal level.

The following is the protocol of a typical experiment:

Albino rabbit. Weight 1.5 kilos. Ether anesthesia. Main ear veins in right ear dissected out and loose threads passed round them. Right cervical sympathetic exposed in the neck for stimulation. Right ear placed on the stage of the microscope and examined. 


\begin{tabular}{|c|c|c|c|}
\hline Time & $\begin{array}{l}\text { Duration of } \\
\text { stimulation }\end{array}$ & Rate of blood flow & Result \\
\hline & seconds & & \\
\hline $10: 31$ & 7 & Normal & Contraction \\
\hline $10: 33$ & 8 & Normal & Contraction \\
\hline $10: 35$ & 7 & Normal & Contraction \\
\hline & \multicolumn{2}{|c|}{ Venous obstruction produced $10: 37$} & \\
\hline $10: 40$ & 13 & $\begin{array}{l}\text { Capillary observed showed } \\
\text { only slight slowing }\end{array}$ & Contraction \\
\hline $10: 42$ & 24 & Marked slowing & No contraction \\
\hline $10: 46$ & 32 & Marked slowing & No contraction \\
\hline $10: 51$ & 28 & Marked slowing & No contraction \\
\hline $10: 57$ & Venous & $\begin{array}{l}\text { One vessel with slight } \\
\text { slowing } \\
\text { Those with marked slow- } \\
\text { ing } \\
\text { ruction removed } 10: 58\end{array}$ & $\begin{array}{l}\text { Contraction } \\
\text { No contraction }\end{array}$ \\
\hline 11:01 & 15 & Slight slowing & Contraction \\
\hline 11:06 & 10 & Almost normal & Contraction \\
\hline $11: 12$ & 6 & Normal & Contraction \\
\hline $11: 33$ & 8 & Normal & Contraction \\
\hline $11: 36$ & 7 & Normal & Contraction \\
\hline
\end{tabular}

There was little doubt that the changes which took place in the capillaries were independent of those taking place in the arterioles. However, it was felt that if a substance could be used which dilated the arterioles but left the capillaries unaffected this possibility could be definitely ruled out. For this purpose acetylcholine was used. Taveau and Hunt (13) first showed the powerful vasodilator action of this substance in extremely dilute solution and Hunt (14) later proved that the action was independent of vasomotor nerves. Dale and Richards, (15) in their classical paper in which they analyzed the action of various vasodilator substances, found that this drug acted powerfully on the arterioles but they were unable to find any evidence of an action on the capillaries. They also showed that the changes produced were not dependent on vasomotor nerves. Acetylcholine has the further advantage that it produces a very marked vasodilatation of the cutaneous vessels. The effect of a single injection of acetylcholine passes off very rapidly so that it was necessary to give a continuous injection in order to maintain a low blood pressure duringthe entire period of stimulation. A solution of acetylcholine 
(1 cc. $=0.002 \mathrm{mgm}$.) was allowed to flow from a burette into the jugular vein at a rate which it had been found in experiments on other rabbits of similar weight would maintain the blood pressure at 20-30 $\mathrm{mm}$. Hg. below normal. It would have been preferable to have had the blood pressure reading on the animal used for the experiment but the many other details which required attention and the fact that the head was used for observation rendered it advisable to eliminate this.

Two experiments were performed in which the procedure was the same as in the previous experiments with the addition of the injection of acetylcholine during the period of stimulation. As a preliminary acetylcholine was injected in each instance without sympathetic stimulation in order to see whether it produced any action on the capillaries. The only effect observed was a slight slowing of the stream. In some instances it was thought that a slight dilatation took place but this was not constant and when seen was so slight that it was uncertain. The changes caused by sympathetic stimulation in these experiments differed from those described above in that during the normal period the marked pallor due to arteriolar constriction was absent or markedly reduced while the latent period before contraction of the capillaries took place was about doubled. Stimulation during the period of congestion was without effect on the capillaries in which the rate of flow was greatly reduced as was found in the other experiments.

\section{DISCUSSION}

The results of the present series of experiments confirm those obtained by previous authors that sympathetic stimulation causes contraction of the capillaries independent of its action on the arterioles. Not only was contraction of the capillaries produced in the normal animal but it also took place after the arterioles had been dilated by acetylcholine. They also showed that a profound modification of the action of the sympathetic nervous system on the capillaries takes place during passive congestion. In marked degrees of congestion the capillaries failed to react to sympathetic stimulation and in the lesser degrees the effect was considerably modified. A similar change has been observed by Lewis (16) in man. He found when the pressure in a cuff round the arm was raised more than from 
40 to $60 \mathrm{~mm}$. Hg. he failed to obtain blanching on puncturing adrenalin (1-1000) into the congested area.

It is of considerable interest to consider the cause of the altered response during passive congestion One possibility is that it may be due to the accumulation of acid metabolites, particularly $\mathrm{CO}_{2}$ in the vessels and tissue spaces. This supposition was mainly suggested by perfusion experiments in which capillary dilatation was produced by acid solutions of much greater acidity than one would find under living conditions. However Krogh (17) has shown that a considerable increase of $\mathrm{CO}_{2}$ in the circulation is without effect on the capillaries while it required the application of very acid mixtures to the frog's tongue to produce any dilatation of the capillaries. As Lewis (16) points out it is improbable that an accumulation in the vessels or tissue spaces of such volatile and weak acids could induce such pro $_{\bar{F}}$ longed effects as these substances would be rapidly removed when normal conditions were restored.

The second possibility that suggests itself is that the profound changes in the capillaries were due to anoxemia. Krogh (17) showed that the changes, which took place in reactive hyperemia following circulatory arrest with complete stasis, were not prevented either in the frog's tongue when it was kept in an atmosphere of pure oxygen so that no cyanosis took place or in the frog's web which was amply supplied with oxygen from the atmosphere. Lewis (16) has demonstrated that this reaction in man takes place after such a short period of stasis as to make it most improbable that it is due to a metabolic change from anoxemia.

The third possibility is that it is due to the accumulation in the tissue spaces during the period of stasis of some substance which acts on the capillaries. Lewis (16) has brought forward strong evidence to show that a non-volatile, slowly diffusible substance is constantly produced by the tissues and that it can produce a profound effect on the capillaries when allowed to accumulate. This he terms "H-substance" but he shows that it is probably histamine as it resembles the latter so closely in its effects. He has also demonstrated that histamine is capable of preventing or abolishing the response of the vessels to adrenalin. This explanation seems to be the most likely for the changes observed in the present experiments. Obstruc- 
tion of the venous flow would permit an accumulation of the dilator substance while the gradual recovery observed would be compatible with the removal of a slowly diffusible product such as the " $\mathrm{H}$ substance."

Although not directly connected with the subject under investigation it was seen that the latent period following sympathetic stimulation before the capillaries contracted was increased when acetylcholine was injected. The changes observed in the capillaries following the injection of acetylcholine when no stimulation of the sympathetic was used were very slight and confirmed the view that the arterioles were mainly responsible for the fall in blood pressure. They did not suggest that the prolonged latent period was directly due to a change in the capillaries. Under normal conditions the arterioles contract after stimulation of the sympathetic and thus prevent fresh blood from entering the capillaries while after acetylcholine the arterioles remain dilated and allow blood to flow freely into the capillaries. Under these circumstances the capillaries would have a greater force to contract against than when a few motionless corpuscles lie in their lumen. Thus the time required for their complete disappearance would become lengthened.

\section{CONCLUSIONS}

1. Peripheral stimulation of the cervical sympathetic caused the capillaries in the rabbit's ear to contract. This effect took place at a definite interval after arteriolar contraction. It was also present when the arterioles were dilated by acetylcholine.

2. The latent period between the commencement of stimulation and contraction of the capillaries was prolonged when acetylcholine was injected throughout the time of stimulation.

3. The production of congestion by venous obstruction caused either failure of the capillaries to contract as a result of stimulation of the sympathetic nervous system or a considerable prolongation of the latent period depending on the degree of stasis in the individual capillaries.

4. It is suggested that individuals with chronic passive congestion show a variation from the normal in their vasomotor reactions, dependent on the degree of stasis. 


\section{BIBLIOGRAPHY}

1. Beale, L. P., Phil. Trans. Roy. Soc. London, 1860, cl, 611. On the Distribution of Nerves to the Elementary Fibres of Striped Muscle.

2. Glaser, W., Das Vegetative Nervensystem, Müller, Berlin, 1920.

3. Steinach, E., and Kahn, R. H., Archiv. f. d. ges. Physiol., 1903, xcvii, 105. Echte contractilität und motorische Innervation der Blutcapillaren.

4. Krogh, A., Harrop, G. A., and Rehberg, P. B., J. Physiol., 1922, lvi, 179. Studies on the Physiology of Capillaries. III. The Innervation of the Blood Vessels in the Hind Legs of the Frog.

5. Hooker, D. R., Physiol. Rev., 1921, 1, 112. Evidence of Functional Activity on the Part of the Capillaries and Venules.

6. Harris, K. E. and Marvin, H. M., Heart 1927, xiv, 135. The Innervation of Mammalian Capillaries by Vasoconstrictor Sympathetic Nerves.

7. Doi, Y., J. Physiol., 1920-21, liv, 227. On the Existence of Antidromic Fibres in the Frog and Their Influence on the Capillaries.

8. Langley, J. N., J. Physiol., 1922-23, lvii, 428. Antidromic Action.

9. Langley, J. N., J. Physiol., 1923-24, lviii, 49. Antidromic Action. II. Stimulation of the Peripheral Nerves of the Cat's Hind Foot.

10. Lewis, T., and Marvin, H. M., Heart, 1927, xiv, 27. Observations Relating to Vasodilatation Arising from Antidromic Impulses to Herpes Zoster and Trophic Effects.

11. Crawford, J. H., J. Clin. Invest., 1926, ii, 365. Studies on Human Capillaries. III. Observations in Cases of Auricular Fibrillation.

12. Crawford, J. H., J. Clin. Invest., 1927, iv, 317. Studies on Human Capillaries. V. Observations in Cases of Heart Disease with Regular Rhythm.

13. Hunt, R., and Taveau, C., Brit. Med. J., 1906, ii, 1788. On the Physiological Action of Certain Cholin Derivatives and New Methods for Detecting Cholin.

14. Hunt, R., Am. J. Physiol., 1918, xlv, 197. Vasodilator Reactions. I.

15. Dale, H. H., and Richards, A. N., J. Physiol., 1918-19, lii, 110. The Vasodilator Action of Histamine and of Some Other Substances.

16. Lewis, T., The Blood Vessels of the Human Skin and Their Responses, London, 1927.

17. Krogh, A., The Anatomy and Physiology of Capillaries, New Haven, 1922. 